Revista Iberoamericana, Vol. LXXIV, Núm. 225, Octubre-Diciembre 2008, 1083-1098

\title{
UNA CONVERSACIÓN PARA NO PERDER EL TIEMPO: EL CASO DE EL DIABLO EN EL PELO DE ROBERTO ECHAVARREN
}

\author{
POR \\ EDUARDO EsPINA \\ Texas A\&M University
}

En una primera lectura que también son las siguientes, El diablo en el pelo, novela de Roberto Echavarren (Montevideo, 1944), funciona como estrategia de retrospección y recuenta, desde un presente figurado, una acción ocurrida varios meses antes de la escritura de la misma. ${ }^{1}$ No obstante, siguiendo las irrupciones del deseo a la caza de un porvenir indefinible (y el deseo casi siempre hace lo mismo) la articulación anecdótica presenta las peripecias del cuerpo interpretadas en pretérito mientras son observadas, interrogadas de cerca, no en el espejo retrovisor (porque los hechos del goce siguen sin ser consumados), sino en tanto privilegia una meta de itinerancia hacia delante, hacia donde ya nada puede verse sino apenas decirse.

De esta manera, el objeto del deseo -dador del título del libro- existe en el recuerdo como posibilidad aún alcanzable: como deseo, no como añoranza. Mediante este uso idiosincrático, permanente y acechante del tiempo narrativo (y del tiempo de la actualidad amorosa), la novela -referente aparte en el contexto hispanoamericano- encuentra puntos de contacto directos con las dos novelas del londinense Paul Holding, The Abomination y Senseless (por cierto, la portada de este libro se parece mucho a la de la edición argentina de El diablo en el pelo), y con la obra del estadounidense Dennis Cooper, quien en libros como Closer, Try, Guide y Period exhibe una similar actitud transgresora de los mecanismos de presentación y motivación de la sexualidad homoerótica a partir de un plan destemporalizante de la realidad, el cual constata las diferencias y el furor oblicuo que une a la vida con lo que se hace de ella, una vez que el tiempo ha sido atomizado, pervertido. En la sexualidad el tiempo no desaparece, pero sus apariencias en estado difuminado son muchas. En todo caso (para que le hagan caso) desaparece para volver aparecer. Su ser transita un sitio dudoso de ya, pero mejor ya no.

1 La primera edición de la novela (2003) se llama Julián, el diablo en el pelo. La segunda edición (2005) tiene varias correcciones introducidas por el autor y se llama El diablo en el pelo. Todas las citas pertenecen a esta última edición y aparecen entre paréntesis. 
Hay obras hispanoamericanas de alternativa homoerótica, con trama o episodios configurantes de un deseo en estado de promesa y dependiente de identidades móviles: Juan Carlos Onetti (El pozo, La vida breve, Dejemos hablar al viento, El astillero), Severo Sarduy (Cobra), Manuel Puig (El beso de la mujer araña, La traición de Rita Hayworth), Reinaldo Arenas (El Central, Arturo, la estrella más brillante, Antes que anochezca), César Aira (El bautismo), Fernando Vallejo (La virgen de los sicarios), José Joaquín Blanco (Las púberes canéforas), Luis Zapata (Las aventuras, desventuras y sueños de Adonis García: el vampiro de la colonia Roma), Pedro Lemebel (sus crónicas urbanas y la novela Tengo miedo torero) y Roberto Echavarren (Ave Roc). Es un resumen somero, hay otras. El diablo está intencionalmente minada de evidencias somáticas sexuales, en tanto el deseo homoerótico asoma en constante plan de exhumación, dejando en la superficie los registros de su trabajo, esto es, exponiendo la autoridad de una visión que confronta promesas y obsesiones de un goce misterioso en busca de representación. Ese goce contiene una asimétrica traza andrógina puesta al servicio de sus expectativas. Para hacerlas cumplir, el escenario social gana preponderancia porque los personajes están bien elegidos. Disponen del dato seductor. Los partenaires son Julián, un taxi boy, un "Lolito", y Tomás, trotaconventos de bares gay.

El diablo en el pelo, estado documental de una pasión con resultados, inventa en el espacio de su trama una temporalidad que le conviene. La quimera de la perfecta inexactitud temporal -la que otorga cuando tiene ganas el deseo somáticoqueda redondeada, mejor dicho completada, y haciendo todo lo posible para ser de la manera como es y quisiera ser (para eso es protagonista de un acto en estado de anhelo). Las formas del deseo deseando ser las del amor (y ser éste) cifran una obra que, expuesta en el estado de sus peculiaridades (la lección viene desde los indicios mismos), genera un orden escritural nuevo, con un sesgo de estilo y osadía sin parangón en la narrativa hispanoamericana:

No soy muy enamoradizo, pero ahora estoy solo. Sabés cómo es la onda gay: salgo dos o tres veces contigo y me aburriste. Ahora no me interesas, me interesa otra bragueta y otra cola. Cuando me voy, creyendo que estamos bien, ¡chac! Una sola vez en veintiséis años rompí yo la relación y he tenido cantidad de relaciones de este tipo. En el cine no sabés el nombre del loco con quien cogiste, porque no se habla. Hablan las manos. La boca chupa. Uno me preguntó: “¿Qué te parece si vamos a casa?” “¿Vivís lejos?” “No: acá por El Gaucho”. "Bueno, vamos”. Eso me pasó una vez sola en el cine. He tenido otras propuestas de salir a la calle pero como la "pieza” no me interesaba, no salí. No son los mismos que van a los bares. El que va al cine es aquel que tiene novia pero se hace coger; entonces precisa algo rápido y poco visible. Vas al baño a penetrar a otro o a hacer la vuelta y media; el masturbarse es en las butacas. Besitos y cariñitos no corren mucho. (136-37) 
Desde un tiempo a todas luces expansivo, actuando críticamente en la traza situada entre el deseo y su objeto, blanco móvil con el pie en el acelerador, y hacia esa genealogía andrógina y representable, se desplaza la narración, sustraída a un punto de vista común verosímil y destacando todo el tiempo sus marcas genealógicas, como diciendo "están allí, esto es lo que pasó". La obra, como le tocó ser en frases características, sale de su clandestinidad sin tener ninguna, narrando una excepción homoerótica sin convenciones ni subordinaciones, y por ello mismo alcanza pronto sus recompensas. La satisfacción culmina en la fuerza de un contenido, sublime y criminal, haciendo de la obra amoldada a sus ganancias una operación disonante, puesto que el plan de la escritura sólo acata la insistencia de ciertas intensidades sexuales que no se cortan (como tampoco Julián su pelo) ni siquiera ante el asomarse inoportuno de la muerte. El autor sintetiza la trama de la historia:

\begin{abstract}
El personaje Julián es una nueva leyenda hecha carne, tanto como Lolita lo fue en su tiempo. Pero a diferencia de Lolita, el personaje no es sólo narrado, no es sólo objeto de los celos del narrador o del protagonista (como la propia Lolita o la Albertine de Proust) sino que deviene también narrador. Un adulto interesado en Julián, Tomás, recorre Montevideo y sus barrios marginales investigando cómo los adolescentes y jóvenes se relacionan entre sí y con otros. Tal el Príncipe Feliz de Oscar Wilde, aprende sólo poniendo en riesgo su integridad física. (contratapa)
\end{abstract}

A través de varios incidentes que culminan en una temporada veraniega en las Sierras deCórdoba, Argentina, Tomás descubrela naturaleza volátil de Julián. Cuando la aventura amorosa alcanza un impasse que parece inevitable, ocurre un giro: el deseo insatisfecho de Tomás, su curiosidad, deviene voluntad de saber acerca de la vida secreta de su ex amante y del mundo en que se desenvuelve. Convence a Julián para que le conceda entrevistas a cambio de dinero. Los encuentros entre esta nueva Sherazade y el periodista gonzo en quien Tomás se ha convertido desencadenan un informe sardónico y duro acerca de las supuestas proezas eróticas y criminales de Julián. A pesar de que el informe suena auténtico en su conjunto podría no ser exacto en los detalles, al fin y al cabo al menos en parte es una invención, considerando que el astuto y ambivalente Julián alimenta a Tomás con lo que éste quiere oír, y por lo que él paga.

Una vez obtenido el testimonio que cree necesitar, Tomás persuade al muchacho para que retome los amoríos. Pronto Julián se enferma de hepatitis. Entonces Tomás empieza a salir con otro, que trabaja en un club nocturno como bailarín e imitador de Michael Jackson. Julián se cura y se reencuentran. Sin embargo, Tomás ya no es inocente. Obseso por las confesiones de Julián, no puede confiar en él, tiene miedo de ser atacado y robado. Además, sigue viendo a "Michael Jackson" como un plan B, un contrapeso para equilibrar las emociones en caso de que el mercurial Julián 
desaparezca de nuevo. Pero en vez de ser asaltado por él, como teme, Tomás es agredido con un cuchillo por quien menos espera: “Michael Jackson”, que pretende robar su coche. Malherido, desangrado, logra a último momento escapar del agresor huyendo hacia la calle. Después de una intervención quirúrgica delicada se recupera en el hospital, vuelve a casa y ajusta una nueva cita con Julián. Mas ahora, al haber atravesado la muerte propia, advierte que la relación con el malandro carece de toda esperanza.

Entonces empieza a ver a Ariel, otro andrógino que, igual que su eventual asesino, es admirador e imitador de Michael Jackson. No parece mal muchacho. Sin embargo, cierto reloj interno decide a Tomás a renunciar también a este recién venido. Termina solo y libre.

A través de los personajes principales y de una multitud de personajes secundarios, a través de los múltiples relatos de Julián, la novela entreteje un universo de relaciones gays, delictivas y de prostitución entre las capas pobres del pueblo. No construye un desiderátum de los derechos humanos del homosexual sino que explora, vívida e implacablemente, "las condiciones reales de la vida erótica y sentimental de los homosexuales latinoamericanos en el presente". ${ }^{2}$

Así pues, situada en una línea de borde, desplazamiento y replanteos, El diablo en el pelo cruza ambos lados de las expectativas: de uno está el paso del tiempo; del otro, sus consecuencias. En medio (no a medias) emerge el deseo como gran fuerza tutorial y fagocitante para intentar evitar, de la manera que se pueda, que ese maremágnum desprolijo que es el tiempo -esté como esté- siempre trabajando $a$ full para seguir fugándose. El deseo (tiempo con objeto y como objetivo) conversa con sus prerrogativas. Tras la ausencia designada con nombre propio la pérdida amorosa que busca representación quiere sentirse justificada. Algo debe decirse para que el todo no quede tan incompleto. El deseo escribe su autobiografía no autorizada. Es sintaxis incrustada en sus iniciativas, mediante las cuales se exhibe como situación en crisis, como cúmulo existencial sin alternativas: porque todo es tiempo, pero sin deseo, nada.

Lo mismo que el viaje hacia muchas partes en la infalible máquina de H. G. Wells, pero menos especulativo, el deseo, sin ser pasatiempo, pasa por el tiempo teniendo a la vida como tránsito hacia delante donde, sin embargo, las amenazas del futuro están en el pasado. La meta, el desiderátum del deseo deseando, es llegar a lo primero sin perder segundos. Y se relatan los pormenores de este traslado. ¿Se puede? La novela articula el principio de la posible respuesta. Todo lo demás será (porque vive de anhelo) continuidad, ningún detenimiento. El diablo instaura pues un mecanismo con empeño de aprendizaje: se trata de empezar desde cero,

2 Entrevista personal con el autor realizada en Montevideo, agosto de 2005. 
desde el cero de la pulsión original (desde el día que se conocieron), a partir de ese nivel ontológico donde en monólogo interior se cruzan el deseo, protegido y transformado hacia su posteridad, con el tiempo en su restante cantidad; su cantidad escrita, instantes para releer:

Con el dedo sobre la arena había escrito: "Viva el amor gay”. Era un deber bien hecho, un intento de halagar a Tomás. La palabra gay sonaba respetuosa, a la vez que simplona. Había trazado sobre la arena esos signos arabizantes. Allí cerca, unos niños dibujaban otras encaracoladas leyendas.

-También ahí dice "Viva el amor gay”-comentó Tomás, riendo. (71)

Escribir es un riesgo. Es hacer una pirueta mortal hacia el lugar de la caída, o propiciarla. Sin embargo, el objetivo (de la escritura) no es caer en la complacencia nostálgica o anhelante propia de la memoria, ni tampoco en la indulgencia autorreferencial, sino verificar el momento cuando los sucesos anteriores de la pasión suceden: registrar el instante de sus cambios, su constancia para transitar por zona de detalles, por ese locus amoenus de pliegues, repliegues y saltos hacia un estar en sitios diferentes. El relato es un viaje por un álbum de fotografías donde los personajes, en lugar de estar fijos (convertidos en clichés del tiempo), se mueven irrecíprocos, yendo hacia donde pudieron estar buscando completar la traza, pulsión, original. Un viaje por los planes inconclusos que no quieren abandonar su condición transitoria.

La historia de Julián, no en vano, tiene una frenética condición fluvial: con los días que se van sumando al porvenir del recuerdo, los protagonistas se desplazan por el río del tiempo, de lecho en lecho. Y este río, que es también éste y el de Heráclito, tiene dos orillas pero en una nadie está: aquella donde el narrador no podrá volver a bañarse. Tiempo aniquilado, un tiempo muerto que el deseo no quiere dejar morir. La que toca es la la orilla del deseo que ha perdido de vista, pero no de voz, a su objeto, incumplido ahora -en el ahora desplazándose en la novela- en tanto permanencia de objetivos, y filtrándose en el devenir temporal como disolución del género y del orden de las "buenas costumbres".

Lo metió en la cama y le exigió una inmediata reparación militar. Lo abrió de piernas, metió la nariz entre los glúteos. ¿Venía de un topetazo con algún otro? En efecto, le pareció que el esfínter estaba mojado. Ahí y entonces lo serruchó sin contemplaciones. (63)

Hay un tiempo para estar quieto, pero no es el del deseo. Tampoco el de esta novela. Un vértigo ante la pregunta imposible de responder empuja la escritura, haciéndola pulsión, pero antes continuación, cifra de una irrepetitibilidad. Las huellas se liberan de sus pasos porque no saben andar de otra manera. Su desplazamiento acata 
sincronías impredecibles. El tiempo que contiene es el de un desahogo existiendo como perpetuo preámbulo. El deseo no es aquello que se cumple, sino lo que está a punto de ser irrealizable. Es un avatar sin certezas pero librado de caducidad. Una constancia de desmesura lo guía apropiándose de él. Y da razones para prescindir de la razón lógica deductiva. Estas son las razones del corazón, y ya sabemos cómo son. Es ésta la principal noción de su actividad proliferante: el deseo existe como dispositivo atemporalizante sucediendo en un lugar que el tiempo quiere abolir y por eso lo intenta:

Ocurría lo siguiente: no solo la imagen del amado se hallaba destrozada desde hacia años en el recuerdo sino que también los ojos, fuerte astigmáticos, de Tomás, reflejaban en ambientes opacos, y más todavía en momentos de emoción, los objetos vistos en planos al principio borrosos, así que Juli hasta ese momento no había tenido ningún rostro todavía. (56)

Mediante una instancia paradojal, de borramiento que invita a quedarse sin saber, a no querer hacerlo (porque es razón y naturaleza del deseo evitar saber qué será lo próximo), el deseo participa como protagonista exclusivo de un acto de cesación de la temporalidad -he aquí otra de sus paradojas-, la que impide que el objeto del deseo sólo devenga deseo. Sus ráfagas en expansión, desacomodándolo, lo impiden. El deseo abre los accesos a lo real, a un compendio cronológico de sucesos que diversifican en la memoria lo vivido, sobrepasando la extensión del relato, que es también la de la propia experiencia.

En esa confluencia de tácticas y ansiedades portátiles marcadas por interrupciones y abreviaciones (todo "muy" táctica del deseo), no solamente el objeto del deseo es el que cambia, sino que el deseo resulta cambiado por situaciones indefinibles que vaticinan la brecha, el umbral, de una transición hacia un sitio, ciclo, concluido pero aún del todo incompleto. El deseo es transformado por sus rotaciones (sigue la ley de su naturaleza), y en su metamorfosis proyecta secuencias, instancias, que distinguen la hora diversa de sus mutaciones. La narración, de intrínseca manera -y en esto radica parte de la agilidad de la novela, que es larga pero que se lee con feliz facilidad-, pregunta una y otra vez hacia dónde se desplazará la realidad una vez que el deseo, arremetiendo en distintas direcciones temporales, empiece a actuar corrosivamente sobre ella. La traza pulsional se autopersigue. Como el uróboros, muerde su cola, se retroalimenta con su entusiasmo enardecido. En ese escenario de imposible regreso hacia donde ya se estuvo, las apariencias que aparecen resultan más falsas de lo que parecen y las cosas con solución de continuidad pueden ir en una u otra dirección despegadas de los acontecimientos. Están libres para ser por primera vez de la misma manera que ya fueron. 
Los cambios contagiosos de autogeneración del deseo afectan la continuidad lineal del tiempo y también a la idea de futuro como tropo acontecible. El deseo genera ideas cuyo marco temporal está marcado por asimetrías y porosidades a través de las cuales se filtran momentos sobrevivientes de la memoria, la cual, lo mismo que el propio tiempo, actúa en todas las direcciones, rebobinándose incluso cuando su actividad temporal es proléptica. Vive en un viceversa; yendo hacia adelante se ve de la manera que era (en imperfecto no en pretérito perfecto). Creyendo en el porvenir de sí mismo, el deseo inventa la punta de su iceberg. No en vano la marcha temporal del deseo funciona como tipping point, conteniéndose y proliferando, por más que la novela está narrada con precisa sobriedad. ${ }^{3}$ No obstante, se aleja del simple acto forénsico de contar únicamente aquello ya ocurrido y conocido para extenderse en las posibilidades de lo que aún sigue sin suceder, aunque se desea que hubiera ocurrido, pues ésta es una historia sobre la temporización voraz del deseo, sobre su vigencia, no sobre el tiempo marchito (domesticado) de la memoria.

En tanto metahistoria del tiempo (la memoir de éste), el relato argumenta una salida como aspiración de infinita posibilidad. Puesto que la aventura es resultado, la narración construye el tipping point de una causa y de un acontecimiento, encontrados en el desarrollo de una pulsión, mitad refulgente, mitad abstracta (el deseo nubla) y a punto de ser comportamiento en toda su nitidez. Es la nitidez de un deseo corto que se reinicia mientras transcurre y que no es (ni quiere ser) recobrado en la escritura como déjà vu interrumpido, ni como equilibrio derrumbado por su realización, sino más bien como tiempo perdido superpuesto a la memoria, esto es, a su constante continuidad en retroceso. No en vano, entre la indecibilidad y lo indescrifrable, las vicisitudes emergen en el plano de reconstrucción narrativa como algo al alcance del entendimiento que solamente puede ser entendido por lo que no es o no pudo -la expresión "creo" se repite- realizarse completamente:

¿Todo el sexo que tuve? No traje el cuaderno. Impresionante. ¿A partir de cuándo era niña, o niño? Son lindos aquellos tiempos. Entonces yo pensaba que era alucinante, pero no lo es, sino algo igual a todo. Podés acostarte con mujeres y con tipos sin creerte que sos un crá ni que es una gran cosa.

El otro día, de tarde, estaba en la biblioteca del liceo. Vi a los pendejos de trece, catorce años, y todos se miraban con ganas. Y ellos no se daban cuenta. ¿Viste cómo es la cosa? Se miran, se manosean jodiendo, pero no se dan cuenta. Creo que lo mismo me pasaba a mí en aquel tiempo, hace cuatro años. (202)

3 Nota del editor. La expresión tipping point podría ser traducida como “punto de inflexión” o "punto crítico"; es el momento a partir del cual algo que era minoritario comienza a propagarse y expandirse, a universalizarse. En Estados Unidos, la expresión se popularizó a partir del libro homónimo de Malcolm Gladwell (2000). 
Telenovela neurótica en pocos capítulos, thriller sangriento, autobiografía sin género, diario íntimo de una pasión sangrienta en primera persona (tiene cartas fechadas y entradas a un cuaderno de vivencias), o historia de amour fou a través de una óptica de periodismo gonzo, o bien todo eso al mismo tiempo en su propio tiempo, El diablo en el pelo es la historia de un deseo somático inspirado por sus acaecimientos (vive para que le sucedan cosas), el cual reemerge para ser cotejado en las marcas de duración por donde ha pasado, abierto a la imaginación de sus momentos, ésos que ya no le pertenecen sino tan sólo como refugio de remembranzas que la escritura al recobrar busca definitivamente interrumpir. Preguntando por lo que quedó de aquello que aún existe, la escritura exhuma acontecimientos de un deseo deseando (proliferando tras la conclusión), y al hacerlo replica la acción del tiempo en un escenario sumergido, uno que no ha perdido su secreta espontaneidad ni tampoco sus deseos -porque también los tiene-de sentirse absuelto de objetivos antes de que termine el libro.

En De Senectute, Norberto Bobbio dice: "El tiempo de la memoria avanza al contrario del real. Los recuerdos que afloran en la reminiscencia son tanto más vivos cuanto más alejados en el tiempo estén aquellos sucesos” (73). Pero aquí el lapso de la reminiscencia es breve, acotado, pues el tiempo transcurrido entre el hecho (inicio del deseo) y la escritura (su reinicio) no ha sido mucho ni desea ser demasiado. Estamos allí, testigos de un hecho en busca de su tiempo, real aunque no lo haya, constatando un proceso mediante la insinuación de los accesos al inventario de la memoria, articulados para ser vistos en un pasado que reaparece en lo que ya mismo es presente. Por esta misma insistencia en construir un porvenir no necesariamente hacia adelante, la distancia genera una casi neutralidad temporal. Caminando a través de una línea recta sin saber si viene o si va, el narrador se "desconfina" de todo propósito circunstancial. Anda con el pasado a cuestas para sentirse parte de algo que la memoria inventa al evocar. Acota Echavarren:

Uno de los procedimientos distanciadores es el paso de la primera persona vivencial a la tercera persona en el relato, paso del yo que suele quedar pegado a los acontecimientos, a un él neutro, que recuerda pero se desliga. A la vez el pasado se viste, se contamina de presente, no sólo por la práctica de la escritura, sino también por la incidencia de las circunstancias actuales sobre los materiales de la memoria. Las circunstancias presentes podrán ser más felices o más frugales, son diferentes en todo caso. El presente hace posible el pasado, el pasado se nutre de nuestro respirar. (Entrevista personal con el autor)

“Laprimera persona vivencial”, la que estuvo, instaura una realidadautobiográfica. Refiriéndose al conjunto de su obra, Fernando Vallejo confesó: "Uno escribe como puede y con lo que tiene. A mí se me hizo que lo más fácil era contar lo que había 
vivido para evitarme el manido trabajo de inventar”. En Arte andrógino escribió Echavarren: "Si nada suplanta la experiencia en el mundo, las obras son objetos inútiles” (105). En El diablo, el despliegue motiva la suplantación de la experiencia, siendo el rescate de esta casi (o sin casi) documental, en tanto, como exigía Echavarren en el libro citado, capta "una estilística de la convivencia, una socialidad de lo singular, de lo marginal”, pero además excepcionaliza su escritura pues define un periplo inaugural en el contexto de la literatura latinoamericana, dando cabida a una mirada de los estratos suburbanos (106).

La novela puede verse sin mayores explicaciones como correlato de una experiencia agónica (no es arbitrario el uso de este adjetivo) padecida por el autor. Así pues, entre la experiencia vivida (1997) y la escritura/publicación de ésta (1999-2003), vale decir, desde el nacimiento del narrador, ha pasado poco tiempo. Por lo tanto, su autenticidad memorialista no se origina en la perspectiva generada por la reminiscencia, sino por el sentido de recuerdo basado en un tiempo aún no concluido, al menos sin concluir en la traza inquieta, proliferante, del deseo. Por eso se desliza a lo largo y ancho de un periplo rutilante: trata de saber el final de un plan cuyo comienzo quizá fue, es, la conclusión. Sobre la superficie emergen imágenes de un fuselaje curioso cuya cosmética carece de advertencias y se mueve igual que el aprendizaje de un anhelo, de una promesa: como bricolage ordenando sus piezas.

Esta salida fulminante del quicio de la razón lógica se hace prevalecer resaltando un desparpajo con recovecos y con la felicidad de haber dado el último paso hacia la disolución de sus intenciones. El deseo es la locomotora -de un tren fantasma- que embiste contra el tiempo. Es la catástrofe física actuando sin timidez, mediante la cual el protagonista cae en la cuenta -es su caída- de que las cosas que al mismo tiempo dejaron de ser aliadas y adversarias pertenecen al territorio sin definiciones de un tiempo muerto representando un deseo aún vivo. Un deseo que desconfía de sus triunfos y fracasos y que en su reaprendizaje mira sin indulgencias, remordimientos ni querellas, sus pasados días en acción, donde los acontecimientos en retrospectiva valen menos de lo que valen porque allí no habita la verdad -imposible que pueda- y el testimonio es subjetivo.

Los lugares visitados por la memoria acompañan la entrada en sus frecuencias: siempre se está allí, no en estado de melancólica criogenia, consecuencia de lo no alcanzado ni alcanzable, sino en tanto deseo que continúa existiendo aunque no haya existido completamente, o sí, pero no ha podido ser abandonado. La historia sigue la salida en cacería de un deseo que se quiere hacer desaparecer, más que en el acto mismo de desear, en la extensión temporal que lo lleva hacia delante mirando para atrás. Los instantes, no el tiempo, representan la totalidad. Son llamados a revivir en el lenguaje una partenogénesis temporal y a preguntarse por qué, sabiendo a priori que no habrá respuestas, y que lo único que puede hacerse es escribir en 
presente sobre algo ya ocurrido y que sin embargo sigue siendo imprevisible, esto es, innombrable.

Ésta es la paradoja que la historia de El diablo presenta: habla sobre un acontecimiento que, misterioso, resiste la indagación, aunque haya dejado de existir, sin presentar razones sobre su pervivencia tenaz, salvo las que el deseo otorga ocultando sus motivos. En todo caso, la narración sugiere, como sugiere desde la primera frase, que las cosas que van a suceder en la historia y que sucedieron en la realidad, sucedieron porque tenían que suceder. Este intencional desconocimiento de causa del espacio temporal surgido entre lo ocurrido y la falta de explicación involucra un tiempo de deriva, que en flashbacks fragmentarios articula la crónica de una indecibilidad, no definitiva, pero en proceso. De allí que el relato se mueva por cronologías parciales, las cuales tensan la duración mediante bifurcaciones y variaciones narrativas que retardan la acumulación temporal.

Se constata el efecto de resonancia: al ser narradas, las cosas ya sucedidas postergan su (re)aparición, generando la inquietud de aquella expectativa propia de un tiempo en pro de algo, no sólo de sí, pues favorece un proceso que no cesa. El tiempo del deseo resulta ser una interioridad controlando la figura del narrador que describe y que constata el desplazamiento de su ilusión de sentido total hacia "ese" momento buscado que en su atemporalidad quiere hacerse específico. El tiempo establece una marca natal, un tajo incurable de origen, en el devenir de los protagonistas, siendo así motor y patrocinio de un estado intrínseco que sabotea cualquier instancia significativa que desde fuera se le quiera imponer a la narración. En tanto escritura en estado de découpage y solivianto, el relato carga los fragmentos dispersos del tiempo recién estrenado con detalles de un deseo que nunca ha sido abandonado; son detalles de un retorno al sitio al cual no puede regresarse, porque es irregresable: "Viajaba a velocidad constante hacia una inequívoca conclusión" (119).

En ese espacio de fuga constante hacia un adentro exterior ni tan lejos ni tan cerca, hacia una temporalidad acotada pero impredecible y contenida en la discontinuidad del instante, el tiempo en posición disociante, autorreferencial, impone una lógica "desconfiguradora", en tanto al problematizar la linealidad de su acontecer modifica aquello que advierte. El tiempo es aleatorio, y puesto que es un tiempo autobiográfico, deja de ser estrictamente cronológico; acepta parches, desvíos y reingresos, salidas deliberadas de la contigüidad. Éste es el gran retruécano de la novela; sucede en una linealidad temporal tradicional, es decir, impone la lógica narrativa (comienzo, desarrollo, conclusión), pero en el transcurso de la misma engancha atajos de tiempo ignorado, no utilizado, tiempo que es metáfora y contención de una contingencia cronológica: la acción sucedió y su efeméride regresa. 
Al insistir en la reverberación incesante de un sentimiento pasional, en los antojadizos motivos de sus gozos pulsionales, la novela es pues una crítica del tiempo; crítica que ordena el ensamblaje performativo del deseo en tanto mecanismo y perspectiva de resonancia. La revisión del papel de éste, del deseo, parte de la especificidad intransigente del tiempo, esto es, de la idea de que su verdad no puede conocerse. Vive únicamente de pautas. De dicho tiempo sabemos que es, pero sus aporías resultan impenetrables, y ni siquiera lo son aquellas que se manifiestan como particularidades cotidianas. El tiempo al que puede accederse, el único en ese tránsito hacia su razón de existir, es el que existe en la novela, aquel exigido y sobredimensionado por el deseo: tiempo que éste pone a disposición de su impostergable actividad, acelerándola o enlenteciéndola, haciéndola inseparable del lugar donde no se puede estar: tiempo moviéndose nervioso, yendo de aquí para acá y más allá a la caza de sus triunfales interrupciones. De esta forma, el tiempo del deseo se convierte en síntoma y sintonía de sus asimetrías, las cuales resultan inseparables de lo que ocurre de una sola vez en la trama, porque es tiempo y es deseo al unísono. Sus apariciones son antes que nada (y la expresión resulta llamativa hablando del tiempo como disolvente de la nada), develamiento de un propósito cambiando de temporalidad pero sin dejar de ser nunca progresión ni de servir al plan de su insistencia, por el cual puede seguir deseando y en/por el deseo sentirse perseguido.

Actuando por saltos retrospectivos, flashbacks y proyeccciones analépticas, el deseo reordena sus instancias precedentes, no para regodearse con actos procedentes, sino para exhumar los planos simultáneos parciales, en apariencia desechables, que ocurrieron al mismo tiempo que ocurría el deseo. Desplazándose hacia un centro situado en la periferia, que está allí pero que se encripta, la escritura arma su paisaje de posibles evidencias, preguntando -en lo que responde-sobre las otras acciones (además de la principal) que deben agregarse a la concatenación de fechas y consecuencias. Esta lectura microscópica del deseo, instalado en los intervalos rememorados, alterna evocación con borramiento, epílogo con posdata, y estructura con esporádica disolución de la narrativa lineal. El ritmo de la retrospección es también introspectivo, en tanto de manera indiscutible el deseo se revela hacia dentro de su estar en perspectiva, hacia un tiempo acontecido aconteciendo, pero que sigue sin suceder completamente y ante el cual se unen varios destinos en uno, sobre todo los varios que tiene el narrador ocurriendo a la manera de reencuentro in medias res consigo mismo.

Este estado de plenitud rebobinándose, de evocación con anhelos pero sin organización cronológica definitiva (y eso que la acción ocurre en el pasado), acude a los cambios de perspectiva, no del material exclusivamente narrativo, sino de la capacidad para intentar entender al deseo mirándolo como futuro anterior. Se quiere saber cómo será y cuál es el futuro de su pasado. Por eso el plan retrospectivo no 
es de evocación sino de salida hacia un tiempo designado cuya duración sucede entre precisos momentos y límites impredecibles, alternativos. La novela articula una exuberancia de pasiones vivas que se resiste a ser momificada y vaga por ello penumbrosa frente a una pantalla que proyecta los estados anímicos y somáticos de un período buscando su continuidad en aquello que la memoria advierte como pulsión inextinguible arremetiendo hacia delante.

El pasado empieza a repetirse (así es como vive y trabaja), por lo tanto se anima a dejar de serlo; su pulso ha entrado nuevamente en ruta. Lo guía una singularidad, un presente sin descontinuar liberándose de la sujeción al ser actual y de la necesidad de tener que protagonizarlo en el plano narrativo, aunque sí en el psicológico, donde el narrador puede ejercer la feliz ignorancia de su desconocimiento: el deseo no puede cazarse, no al menos con las redes de la razón. El narrador, engañado por la seguridad que da un no-conocimiento imposible, se instala dentro del tiempo que no se sabe bien cómo es y que a veces va hacia delante y otras hacia atrás, pues el deseo altera las regiones temporales de su actividad, como buscando realizar que la novedad suceda en la repetición, que es en donde ocurre.

Tiempo en estado de collage que enlaza los distintos fragmentos de una unidad por separado, estableciendo los momentos regresivos sucesivos del deseo, ahora transformado en dispositivo sin solución de continuidad (salvo en las continuas y engañosas copias que fabrica la memoria). En esta construcción sin arrepentimiento que desvía la congruencia hacia lo que ha sido y hacia aquello que todavía está siendo, el tiempo, deseando todo el tiempo ser otro (la novela construye una verdad acerca de la relación entre deseo y género), cambia de comportamiento, hace "como que sí pero no" para preexistir a cuanto pudo haber acontecido. Esta paradoja en alerta, que evoca la sentencia de Wittgenstein (de lo que no se sabe no ha de hablarse), queda traducida así: sobre aquello que no dejó de desearse no debe hablarse de olvido. Por lo tanto, en esa sucesión estratificada donde se sigue deseando desear, nada cambia más de lo necesario y el ensamblado de épocas y paisajes surgidos en la intimidad con alrededores del narrador (los tatuajes de su memoria), expanden un horizonte de imágenes confesionales de las que aún puede hablarse como sitio sin ocupar, todavía disponible.

Ese ensamblado recuerda que el tiempo cronológico es uno corto y que en su intento de absorción desune lo que el deseo no ha querido ni podido separar. El resultado, mejor dicho las consecuencias narrativas de la actividad de un deseo que desea (haciéndolo dentro de un tiempo sin deslocalizarse), es un palimpsesto de recuerdos, obsesiones y correcciones ocurriendo en el escenario de la percepción: la memoria queda anulada por los sentimientos adonde siempre está llegando, aunque nunca haya llegado. La restitución del anhelo original guía la intrínseca travesía de un deseo, bífido en su notoriedad sin suavizar. 
El regreso narrativo a escenas convocadas expande la sintaxis de los sentimientos como fuente generadora de referentes temporales que actúan de manera concomitante para diversificar los efectos de densidad del deseo, en tanto éste se mira idéntico pero irreconocible al mismo tiempo en un tiempo diferente, en el espejo siléptico y transparente de su pasado. Puesto que las cosas vividas no tienen una forma aún establecida, sino dejarían de ser objetos del deseo, cabe entonces inventarles una diferente todo el tiempo. Es lo que hace la escritura: existe en sus exhumaciones. Y éstas se asoman convencidas tras un propósito utópico con consecuencias. Es por ello que en su morfología de práctica somática anfibia, tan adecuada a circunstancias reales, el deseo construye mecanismos temporales que superponen una época reciente a otra, extendiéndose en variantes donde también el azar disemina sus recuerdos, esto es, los efectos particulares de una actuación con detalles.

La novela funciona pues en el espacio de una periodicidad de retornos (hacia los que está yendo), reivindicados, antes que por la actuación de su silepsis, por el movimiento hacia la repetición de un tiempo idealizado por su entrópico movimiento. Confiere a la escritura el estatus de punto de vista en busca de autonomía y de una imagen alternativa de sí misma. Situado en las suturas de una temporalidad anómala, visto ahora sin objeciones, el deseo trabaja para desanclarse de lo que fue para poder ser nuevamente (el eterno retorno a un nuevo origen). Rompe con el tiempo para reinventarlo y reinventarse, rotando en la constante inestabilidad de sus modales y modalidades, en la medida de lo inesperado, problematizadas ambas por la enunciación y las coincidencias autobiográficas en ella reportadas. La escritura abre una puerta a las asimetrías temporales, inseparables de sus consecuencias a priori y a posteriori.

En El diablo en el pelo, el pasado es un lugar de formas a medias, repudiadas y proyectadas sobre un tiempo visualizado como unidad a regañadientes, aunque más no sea hipotética, de imaginación y memoria actualizadas por un orden nuevo, el cual recuenta y sostiene los saltos del deseo hacia su inextricable porvenir (¿estará atrás, adelante?), uno que al ser contado se despliega como rompecabezas de contigüidades. El deseo ejemplifica el continuum de una simultaneidad siléptica, esto es, instalada en la fábrica de anhelos y recuerdos originados en la sensibilidad de los instantes que ahora corresponden a un idéntico plan de coexistencia. Es la arquitectura sensorial de un descubrimiento hacia delante. Pasado y presente son lo mismo: la posibilidad para inventar un futuro ya advertido. No en vano, la novela rastrea los cambios ocurridos en los intersticios temporales, allí donde la contigüidad sin averías busca en la proliferación la unidad sensible y la apariencia fantasmática de su identidad, tras la cual sale la escritura en plan de indagación.

Aunque el relato transcurre en las marcas temporales dejadas por una cronología de acontecimientos in medias res, instala el verdadero marco de interés de la trama y 
del lenguaje en un espacio a-cronológico, en una ucronía originada por los estrenos de reminiscencias del deseo. El inventario de simultaneidades se sobrecarga, originando a su antojo una narración en zigzag, que borrando huellas otra vez las reestablece. Un plan que acontece en el cine muerto de ciertas expectativas, pues la realidad del deseo sufrió un examen forénsico para intentar conocer y constatar mejor la realidad de las cosas vividas que, si bien sucedieron, aún no son definitivas.

La autopsia del cuerpo vivo ocurre como acto de reducción y expansión en un escenario microscópico, por momentos incluso panóptico, estereoscópico, pues se desplaza hacia la busca de fusionar los diversos aspectos de una tentativa. Todo esto tiene lugar en un escenario escarpado, con rupturas frásticas que absorben la unidad a su manera, como si en el plano de la memoria quisieran devolverle al deseo su condición de instantaneidad inmediata, aunque no lineal, satisfecha, asimilable ni intercambiable, puesto que nunca es el mismo aunque antes ya haya sido. Pero, por más que pudiera dar la impresión de que la narración se desplaza en un tiempo de deriva, de surf, de ausencia de pronósticos, la impresión es errónea. Tal aparente estado de errancia no existe, pues la trama, tal como se destacó, sigue un orden narrativo tradicional, manteniendo el esquema de principio, medio y fin.

Se trata en todo caso de articular el complejo movimiento de una temporalidad que rechaza ser entendida fuera de su dispersión, de una profusa visualidad anatómica atravesada por preguntas sobre lo acontecido. Pero, ¿pasó realmente así? ¿En qué momento los recuerdos empezaron a devenir diferentes, como otros, absorbidos por el accionar en atropello del deseo? Lo más seguro -lo dice la narración- es que no se sabe. Y dentro de ella, retórica del goce, se convoca todo: lo que sí fue con lo que todavía es quizás (para que de esta forma sea menor el margen de error). La omnipresencia de lo fantasmático está en línea directa con el Sade de Los 120 días de Sodoma y con los mejores episodios de Genet. La evocación arremete contra la asimetría de los extremos, allí donde el tiempo cobija períodos diferentes, los hechos bellos de la anatomía cuando ya nada les falta. Es un tiempo ocurrido en bastardilla, puesto que su pasado depende de su actualidad en las antípodas, y sus referencias de realidad de un paradigma incompleto.

Dada esta mecánica de observación (inquisitiva por ser distorsionada), el presente nunca puede ser captado uniformemente, pues su linealidad es porosa, atravesada por rastros emocionales de periplos anteriores. En definitiva, el presente es el único tiempo de la escritura, pues en él coinciden lo prospectivo y lo retrospectivo, figurando una geometría atemporal, no porque allí el tiempo falte, sino porque allí es discutido, transgredido, instalado en ese tenue borde donde empieza a quedar abandonado, pues de esa manera puede ser visto otra vez como situación inicial. La escritura se distancia de su tiempo para poder observarse (la temporalidad: espejo transparente), existiendo como orden intrusivo en una realidad preexistente, 
subordinada únicamente a sus transformaciones. Desde una ubicuidad práctica, con puntos de contacto con la estructura del diario íntimo, de la síntesis autobiográfica -lo es-, la narración se pauta y pacta por fragmentos acumulativos sucesivos, que generan no obstante un mismo tapiz temporal, esto es, una simultaneidad de conflictos coincidiendo en igual eje de estados temporales, ese que el deseo privilegia cuando pasa de la evocación de sus apariciones pasadas al reestablecimiento de su actividad. Existe como solución de subjetividad y como tal regresa reinventado, para presentarse nuevamente reciente en intervalos conectados al anhelo, o ansiedad, ante lo que pudiera pasar, y a la nostalgia por lo que ya pasó, sin que exista una distancia temporal entre una y otra instancia.

Duración presente y acontecimientos evocados se alternan en el carpe diem de su necesidad por separar la ficticia trama uniforme que la realidad pretende imponer, mejor dicho, para instaurar la separación sin riesgos entre plano evocado y plano acontecible. La progresión (porque el deseo no duerme), va separando lo que construye, haciendo que en la memoria los momentos correspondan a sus apariciones futuras; lo familiar y lo impredecible quedan contenidos en la misma morfología del tiempo, descubiertos en sus direcciones privilegiadas, en sus diversos estados de multitemporalidad ensamblada por un único propósito y cuya aparente incoherencia es dispuesta por el estado natural del deseo, sobre el cual todo puede decirse y pensarse, insoslayable en tanto motor de su propia velocidad, siendo ésta uno de los protagonistas textuales: la escritura impone otro orden de velocidad de lectura. En esa intrépida ruta de ritmos sin finalidad se define como catáfora que evidencia peculiares estados de ánimo, como también las idas y venidas del sentimiento rebobinado en la interioridad somática del tiempo: "La enigmática sonrisa de Julián, moviéndose en círculos, le hizo rebobinar todas las etapas del descenso" (129). Este “descenso" es en el tiempo, punto de partida hacia una meta inalcanzable: "Más tarde, el mismo día” (131); "Esa foto fue tomada tres años atrás me parece” (134); "Es el 16 de mayo de 2005” (163, en la primera edición: “Es el 16 de mayo de 2003”); “Fue cuando empecé a no pasar nunca de año” (164); “Yo tomaba merca en aquel tiempo" (169); "En aquel tiempo" (180); "De eso hará un año y medio” (181); “El otro día, de tarde” (202).

El diablo en el pelo, zona lúdica de contrapuntos, de muerte del hombre y la mujer, es también deriva de las expansiones temporales del deseo. Éste, fuente de obsesión, reducción y perversión, arrastra hacia delante, hacia un momento consuetudinario donde resulta imposible quedarse; no marcha hacia su disolución siguiendo planes establecidos: transcurre, dando cuchilladas de instantaneidad, de movimientos con cambiantes resultados, pasando del impasse, del still image, al aceleramiento, proyectando, mejor dicho, llevando consigo una simultaneidad animada por el riesgo de tener que definirla. Y sin embargo, es la regularidad de la 
repetición que deviene sincronía y que impone un tiempo disparatado, disparado y disfrazado, que actúa en los acontecimientos posibles mediante momentos separados de su vigencia, los cuales existen recíprocamente al borde de la disolución pero, por sobre todo, en el umbral de su segundo debut. Se trata pues de vivir otra vez todo, incluso lo todavía no vivido. Es la ansiedad ante el exceso de expectativas, la cual se expresa contradictoriamente: se posterga la vuelta al pasado ("Era prematuro preocuparse del regreso", 106), pero, indefectiblemente, ahí se regresa: "No tuvo más remedio que volver atrás” (106).

Vaya (otra) paradoja: los ecos son posibles en la voz que aún no ha dicho nada y que terminará a solas, revisitando la suposición vivida. El objeto (del deseo) queda todo el tiempo intacto; sin despeinar. En el mar memorioso de su expansión, reserva de surplus, el deseo trabaja voluntariamente uniendo la familiaridad de sus fragmentos desde el interior de los mismos, pues éstos representan la continuidad de su apócrifo calendario, encriptándose y reapareciendo como oscilación, descenso y ascenso hacia la misma vez de un tiempo irremediablemente similar.

Queda entonces sabido para poder saberlo. Siendo como es, cacería de goces, ilación de estados de ánimo animados por el deseo y su visión psicogeográfica (en tanto lo narrado vincula la experiencia sexual de los protagonistas con el espacio social donde se desarrolla), El diablo en el pelo resulta pues un pivote trasgresor de las maneras de narrar el tiempo muerto de la realidad en proceso, a tutti dare y a tutti plen, una realidad donde sólo las cosas coincidentes en su diferencia tienen vida propia, y donde el presente hace posible el pasado para que así -a dúo- el porvenir no deje de ser acontecimiento.

\section{BIBLIOGRAFÍA}

Bobbio, Norberto. 'De Senectute’y otros escritos biográficos. Esther Benítez, trad. Madrid: Taurus, 1997.

Echavarren, Roberto. Arte andrógino. Estilo versus moda en un siglo corto [1998].

Caracas: Excultura, 2003.

El diablo en el pelo. Buenos Aires: El Cuenco de Plata, 2005. Julián, el diablo en el pelo. Montevideo: Trilce, 2003.

Entrevista personal. Montevideo, agosto de 2005. 